\title{
Invitation for submission of manuscripts
}

The December 2014 issue of Powder Diffraction (PDJ) will have a special section on the topic of scientific software. The editors of PDJ would like to invite authors to submit articles on new and improved software in PDJ. Articles on commercial software, which would primarily describe programs that must be purchased for academic use must present information that would be of use to readers that do not have access to the software, such as a general discussion of methods or novel implementation ideas.

In addition, we are looking for individuals or teams who are willing to write comprehensive reviews of the actively used software tools in areas such as area detection calibration and data reduction, powder pattern indexing and Rietveld analysis. Potential authors are encouraged to contact the issue editor, Brian Toby (brian.toby@anl.gov) and/or the Editor-in-Chief (Interim), Thomas Blanton (tblanton@icdd.com) to discuss their ideas further before starting work. Articles will need to be received by June 1, 2014.

Brian H. Toby Editor of Crystallography Education 